\title{
Quantitative Spectroscopic Analysis of Water Populations in the Hydrated Nanopore Environments of a Natural Montmorillonite
}

Sabrina E. Kelch, ${ }^{1,2}$ Randall E. Youngman, ${ }^{3}$ Eric Ferrage, ${ }^{4}$ Jade J. Basinski, ${ }^{2}$ Jiaxing Wang, ${ }^{2}$ Ludmilla Aristilde ${ }^{2,5}$

${ }^{1}$ Dept. of Soil and Crop Sciences, School of Integrative Plant Science, Cornell University, Ithaca, NY 14853 USA

2 Dept. of Civil and Environmental Engineering, McCormick School of Engineering and Applied Science, Northwestern University, Evanston, IL 60208 USA

${ }^{3}$ Science and Technology Division, Corning Incorporated, Corning, NY 14831 USA

${ }^{4}$ Institut de Chimie des Milieux et Matériaux de Poitiers (IC2MP-Hydrasa), UMR 7285 CNRS-Université de Poitiers, 86073 Poitiers, France

${ }^{5}$ Dept. of Biological and Environmental Engineering, Cornell University, Ithaca, NY 14853 USA

(*correspondence: ludmilla.aristilde@northwestern.edu) 


\section{SI Figure List:}

A- XRD Profiles and pore abundance graphs for MONT washed and loaded with 100 $\mathrm{mM}$ and $10 \mathrm{mM} \mathrm{NaCl}$ as well as all $33 \% \mathrm{RH}$ samples

Table A- D001 and FWHM table including washed sample (expanded version of one in main text)

B- XRD Profiles including MONT loaded with 50 and $80 \mathrm{mM} \mathrm{NaCl}$

Table B- D001 and FWHM table including MONT loaded with 50 and $80 \mathrm{mM} \mathrm{NaCl}$

C- XRD Profiles of MONT loaded with $\mathrm{NaCl}$ and buffers

Table C- D001 and FWHM table of MONT loaded with $\mathrm{NaCl}$ and buffers

D- Raw XRD overlaid with model line fits

E- Water mass loss TGA-MS graphs all samples 0-300 with pie charts

Table D- Water mass loss totals

F- Water mass loss TGA-MS graphs all samples 0-1500

G- TICs of all samples

$\mathrm{H}$ - EICs of all samples

I- TGA, DTG, DTA, and DDTA of all samples

$J$ - MNOVA line fit models of all samples overlaid with NMR spectra

Table E- Peak position table for Na NMR

K- MONT loaded with bicarbonate and acetate ${ }^{23} \mathrm{Na}$ NMR (all humidity)

L- 33\% RH MONT loaded with bicarbonate and acetate washed versus unwashed ${ }^{23} \mathrm{Na}$

NMR

M- MONT loaded with 50 and $80 \mathrm{mM} \mathrm{NaCl}{ }^{23} \mathrm{Na}$ NMR spectra and linefits

$\mathrm{N}$ - References NMR spectra

O. RH equilibrated $\mathrm{NaCl} \mathrm{Na} N M R$ spectra and MONT loaded with $100 \mathrm{mM} \mathrm{NaCl}$ with 6.7 ppm bar 

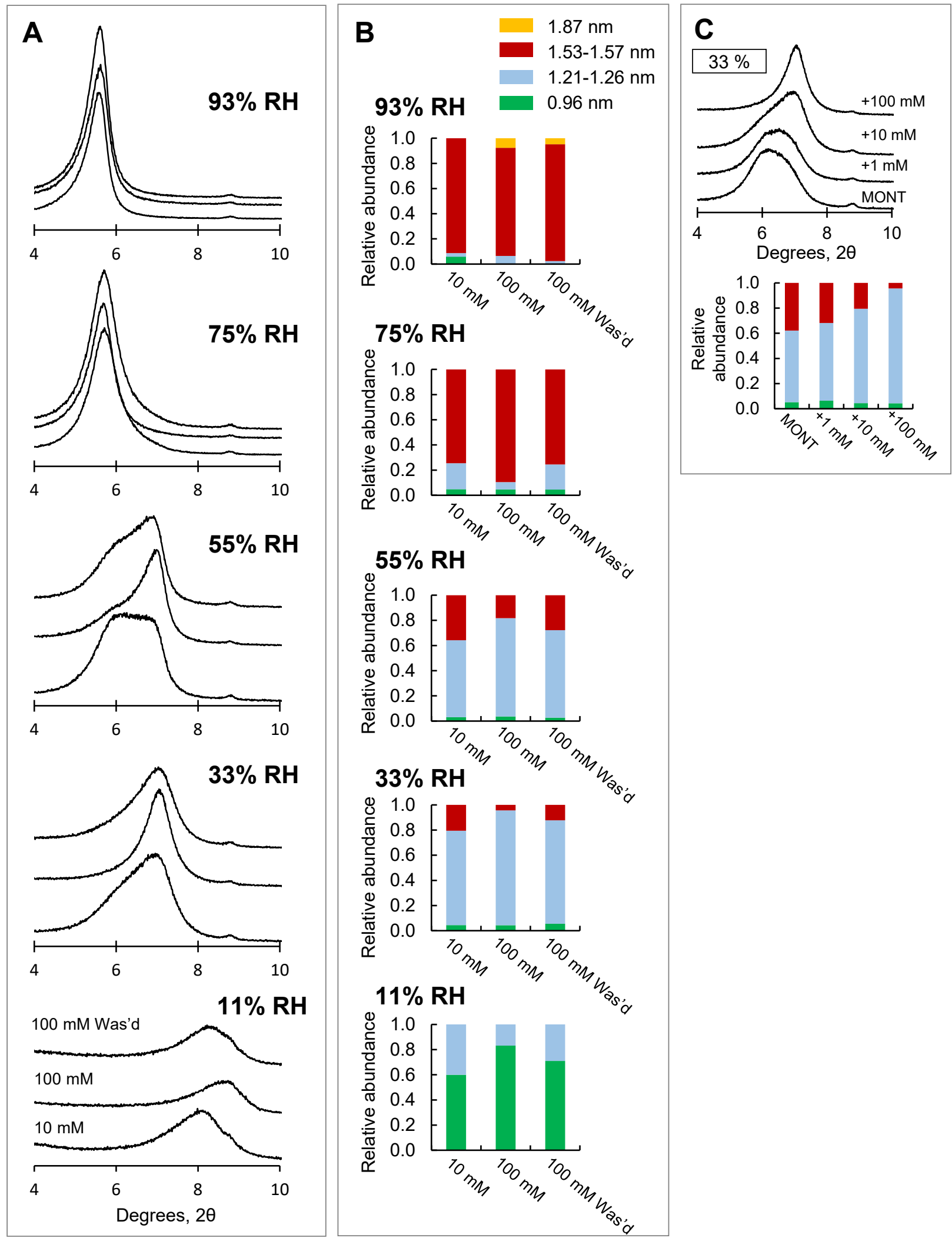

SI Figure A. Modeling moisture-dependent X-ray diffraction profiles of MONT loaded with 10 or $100 \mathrm{mM} \mathrm{NaCl}$ as well as MONT loaded with $100 \mathrm{mM} \mathrm{NaCl}$ with an additional washing step. B. The different interlayer sizes used in the modeling are represented by green bars $(0.96 \mathrm{~nm})$, light blue bars $(1.21-1.26 \mathrm{~nm})$, dark red bars $(1.53-1.57 \mathrm{~nm})$, and yellow bars $(1.87 \mathrm{~nm})$. C. X-ray diffraction patterns of MONT control (no added sodium) and MONT loaded with 100, 10, or $1 \mathrm{mM} 3$ $\mathrm{NaCl}$ at $33 \% \mathrm{RH}$. 


\begin{tabular}{|c|c|c|c|c|}
\hline \multicolumn{5}{|l|}{$93 \% \mathrm{RH}$} \\
\hline & $\mathrm{NaCl}(\mathrm{mM})$ & $d_{001}$ & $\Delta d$ & fwhm \\
\hline & 0 & 1.59 & - & 0.587 \\
\hline & 1 & 1.59 & 0.0070 & 0.519 \\
\hline & 10 & 1.58 & 0.011 & 0.537 \\
\hline & 100 & 1.58 & 0.015 & 0.562 \\
\hline & 100 washed & 1.58 & 0.013 & 0.534 \\
\hline \multicolumn{5}{|l|}{$75 \% \mathrm{RH}$} \\
\hline & $\mathrm{NaCl}(\mathrm{mM})$ & $d_{001}$ & $\Delta d$ & fwhm \\
\hline & 0 & 1.57 & - & 0.590 \\
\hline & 1 & 1.56 & 0.010 & 0.592 \\
\hline & 10 & 1.55 & 0.026 & 0.727 \\
\hline & 100 & 1.56 & 0.014 & 0.615 \\
\hline & 100 washed & 1.55 & 0.026 & 0.716 \\
\hline \multicolumn{5}{|l|}{$55 \% \mathrm{RH}$} \\
\hline & $\mathrm{NaCl}(\mathrm{mM})$ & $d_{001}$ & $\Delta d$ & fwhm \\
\hline & 0 & 1.52 & - & 0.860 \\
\hline & 1 & 1.51 & 0.0070 & 0.962 \\
\hline & 10 & 1.38 & 0.14 & 1.71 \\
\hline & 100 & 1.28 & 0.24 & 0.827 \\
\hline & 100 washed & 1.30 & 0.22 & 1.45 \\
\hline \multicolumn{5}{|l|}{$33 \% \mathrm{RH}$} \\
\hline & $\mathrm{NaCl}(\mathrm{mM})$ & $d_{001}$ & $\Delta d$ & fwhm \\
\hline & 0 & 1.40 & - & 1.48 \\
\hline & 1 & 1.35 & 0.053 & 1.49 \\
\hline & 10 & 1.29 & 0.12 & 1.49 \\
\hline & 100 & 1.28 & 0.12 & 0.725 \\
\hline & 100 washed & 1.25 & 0.15 & 1.11 \\
\hline \multicolumn{5}{|l|}{$11 \% \mathrm{RH}$} \\
\hline & $\mathrm{NaCl}(\mathrm{mM})$ & $d_{001}$ & $\Delta d$ & fwhm \\
\hline & 0 & 1.16 & - & 1.01 \\
\hline & 1 & 1.15 & 0.012 & 0.919 \\
\hline & 10 & 1.10 & 0.065 & 1.24 \\
\hline & 100 & 1.03 & 0.13 & 1.12 \\
\hline & 100 washed & 1.07 & 0.088 & 1.17 \\
\hline
\end{tabular}

${ }^{a} \mathrm{RH}$, relative humidity $(\mathrm{RH})$ for in situ moisture-dependent $\mathrm{X}$-ray diffraction measurements; fwhm, full width at half-maximum; $d_{001}$, the basal spacing of the clay layers shown in $\mathrm{nm} ; \Delta d$, difference in interlayer spacing relative to the control MONT. 

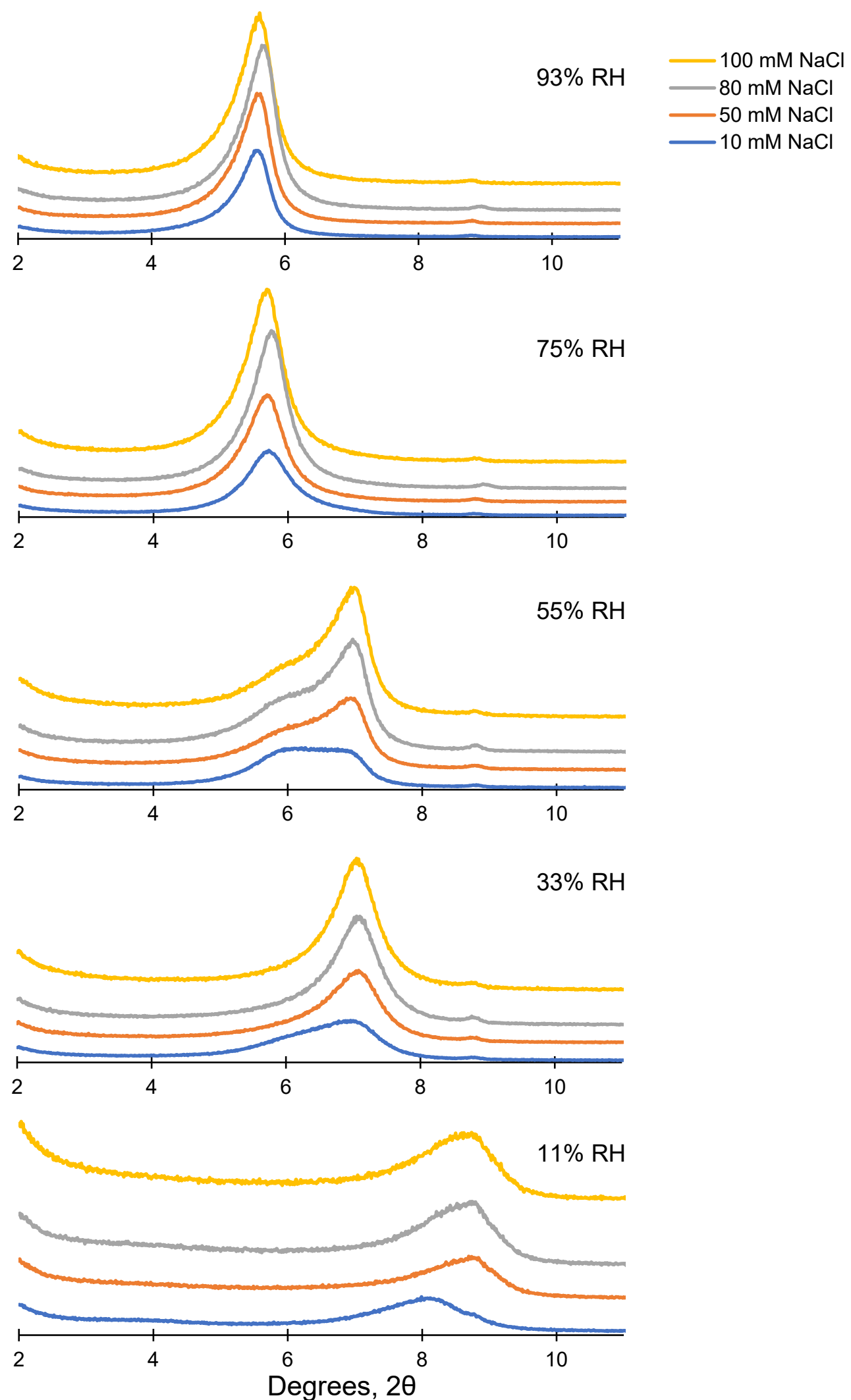

SI Figure B. X-ray diffraction patterns of MONT loaded with 50 and $80 \mathrm{mM}$ $\mathrm{NaCl}$ 
SI Table B. Results from Experimental X-ray Diffraction Patterns of MONT loaded with 10, 50, 80, and $100 \mathrm{mM} \mathrm{NaCl}^{\mathrm{a}}$

\begin{tabular}{cccc}
\multicolumn{5}{c}{$93 \% \mathrm{RH}$} \\
\hline sample & $d_{001}$ & $\Delta d$ & fwhm \\
$10 \mathrm{mM} \mathrm{NaCl}$ & 1.58 & - & 0.537 \\
$50 \mathrm{mM} \mathrm{NaCl}$ & 1.58 & 0.002 & 0.546 \\
$80 \mathrm{mM} \mathrm{NaCl}$ & 1.58 & 0.000 & 0.531 \\
$100 \mathrm{mM} \mathrm{NaCl}$ & 1.58 & 0.004 & 0.562
\end{tabular}

\begin{tabular}{crcc}
\multicolumn{5}{c}{ 75\% RH } & & \\
\hline sample & $d_{001}$ & $\Delta d$ & fwhm \\
$10 \mathrm{mM} \mathrm{NaCl}$ & 1.55 & - & 0.727 \\
$50 \mathrm{mM} \mathrm{NaCl}$ & 1.55 & 0.0060 & 0.654 \\
$80 \mathrm{mM} \mathrm{NaCl}$ & 1.56 & 0.010 & 0.584 \\
$100 \mathrm{mM} \mathrm{NaCl}$ & 1.56 & 0.012 & 0.615
\end{tabular}

\begin{tabular}{cccc} 
& & & \\
& $55 \% \mathrm{RH}$ & & \\
\hline sample & $d_{001}$ & $\Delta d$ & fwhm \\
$10 \mathrm{mM} \mathrm{NaCl}$ & 1.38 & - & 1.71 \\
$50 \mathrm{mM} \mathrm{NaCl}$ & 1.28 & 0.094 & 1.16 \\
$80 \mathrm{mM} \mathrm{NaCl}$ & 1.27 & 0.11 & 0.838 \\
$100 \mathrm{mM} \mathrm{NaCl}$ & 1.28 & 0.095 & 0.827
\end{tabular}

\begin{tabular}{cccc} 
& & & \\
& $33 \% \mathrm{RH}$ & & \\
\hline sample & $d_{\text {o01 }}$ & $\Delta d$ & fwhm \\
$10 \mathrm{mM} \mathrm{NaCl}$ & 1.29 & - & 1.49 \\
$50 \mathrm{mM} \mathrm{NaCl}$ & 1.25 & 0.032 & 0.854 \\
$80 \mathrm{mM} \mathrm{NaCl}$ & 1.25 & 0.039 & 0.723 \\
$100 \mathrm{mM} \mathrm{NaCl}$ & 1.28 & 0.0050 & 0.725
\end{tabular}

\begin{tabular}{cccc}
\multicolumn{4}{c}{$11 \% \mathrm{RH}$} \\
\hline sample & $d_{001}$ & $\Delta d$ & fwhm \\
$10 \mathrm{mM} \mathrm{NaCl}$ & 1.10 & - & 1.24 \\
$50 \mathrm{mM} \mathrm{NaCl}$ & 1.01 & 0.081 & 1.00 \\
$80 \mathrm{mM} \mathrm{NaCl}$ & 1.02 & 0.073 & 1.06 \\
$100 \mathrm{mM} \mathrm{NaCl}$ & 1.03 & 0.064 & 1.12
\end{tabular}

${ }^{a} \mathrm{RH}$, relative humidity $(\mathrm{RH})$ for in situ moisture-dependent $\mathrm{X}$-ray diffraction measurements; fwhm, full width at half-maximum; $d_{001}$, the basal spacing of the clay layers shown in $\mathrm{nm} ; \Delta d$, difference in interlayer spacing relative to the control MONT. 
SI Table C. Results from Experimental X-ray Diffraction Patterns of MONT loaded with $\mathrm{NaCl}$ and in Buffer Solutiona

\begin{tabular}{cccc}
\multicolumn{4}{c}{ MONT control } \\
\hline \%RH & $d_{\text {o01 }}$ & $\Delta d$ & fwhm \\
93 & 1.59 & - & 0.587 \\
75 & 1.57 & 0.022 & 0.590 \\
55 & 1.52 & 0.076 & 0.860 \\
33 & 1.40 & 0.19 & 1.48 \\
11 & 1.16 & 0.43 & 1.01
\end{tabular}

$20 \mathrm{mM}$ Bicarbonate $100 \mathrm{mM} \mathrm{NaCl}$

\begin{tabular}{cccc}
\hline$\% \mathrm{RH}$ & $d_{001}$ & $\Delta d$ & fwhm \\
93 & 1.57 & - & 0.558 \\
75 & 1.55 & 0.0270 & 0.588 \\
55 & 1.27 & 0.303 & 0.739 \\
33 & 1.26 & 0.316 & 0.634 \\
11 & 1.03 & 0.541 & 1.09
\end{tabular}

$20 \mathrm{mM}$ Bicarbonate $100 \mathrm{mM} \mathrm{NaCl}$ washed

\begin{tabular}{cccc}
\hline$\% \mathrm{RH}$ & $d_{001}$ & $\Delta d$ & fwhm \\
93 & 1.58 & - & 0.545 \\
75 & 1.54 & 0.0500 & 0.747 \\
55 & 1.28 & 0.310 & 0.928 \\
33 & 1.25 & 0.339 & 0.887 \\
11 & 1.05 & 0.540 & 1.08
\end{tabular}

\begin{tabular}{cccc}
\multicolumn{4}{c}{$20 \mathrm{mM}$ Acetate $100 \mathrm{mM} \mathrm{NaCl}$} \\
\hline \%RH & $d_{001}$ & $\Delta d$ & fwhm \\
93 & 1.57 & - & 0.561 \\
75 & 1.57 & 0.00900 & 0.579 \\
55 & 1.28 & 0.296 & 1.38 \\
33 & 1.26 & 0.319 & 0.701 \\
11 & 1.10 & 0.475 & 1.09
\end{tabular}

$20 \mathrm{mM}$ Acetate $100 \mathrm{mM} \mathrm{NaCl}$ washed

\begin{tabular}{cccc}
\hline \%RH & $d_{001}$ & $\Delta d$ & fwhm \\
93 & 1.58 & - & 0.543 \\
75 & 1.55 & 0.0310 & 0.700 \\
55 & 1.29 & 0.289 & 1.23 \\
33 & 1.26 & 0.324 & 0.928 \\
11 & 1.05 & 0.530 & 1.09
\end{tabular}

a RH, relative humidity $(\mathrm{RH})$ for in situ moisture-dependent $\mathrm{X}$-ray diffraction measurements; fwhm, full width at half-maximum; $d_{001}$, the basal spacing of the clay layers shown in $\mathrm{nm} ; \Delta d$, difference in interlayer spacing relative to the control MONT. 
* Experimental Data Model Fit

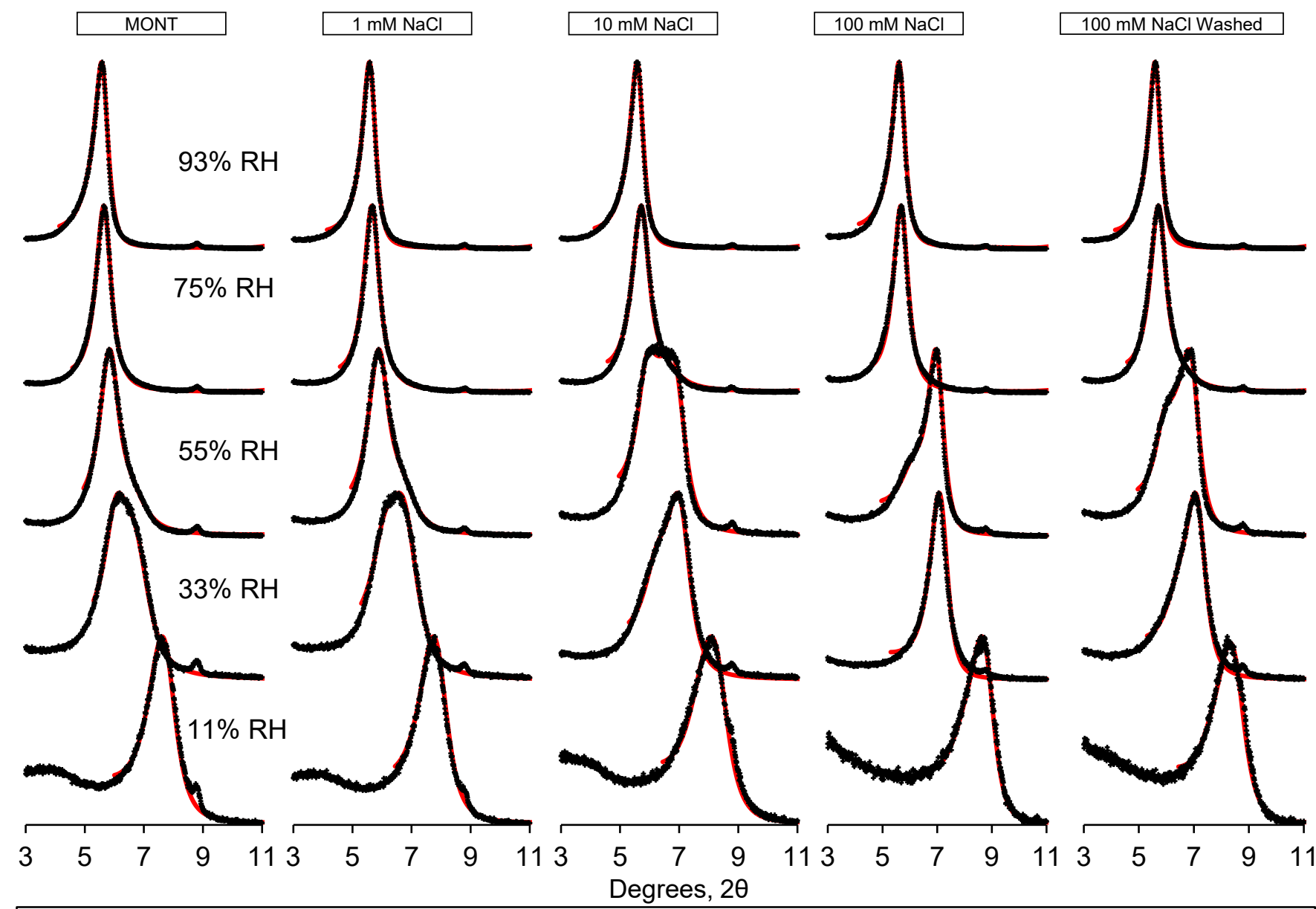

SI Figure D. Moisture-dependent X-ray diffraction profiles and model fits of MONT alone and MONT loaded with 1,10 , or $100 \mathrm{mM} \mathrm{NaCl}$ as well as MONT loaded with $100 \mathrm{mM} \mathrm{NaCl}$ with an additional washing step. The experimental XRD patterns (as black symbols) are overlaid on the associated model fits (red lines). 
$93 \%$ RH

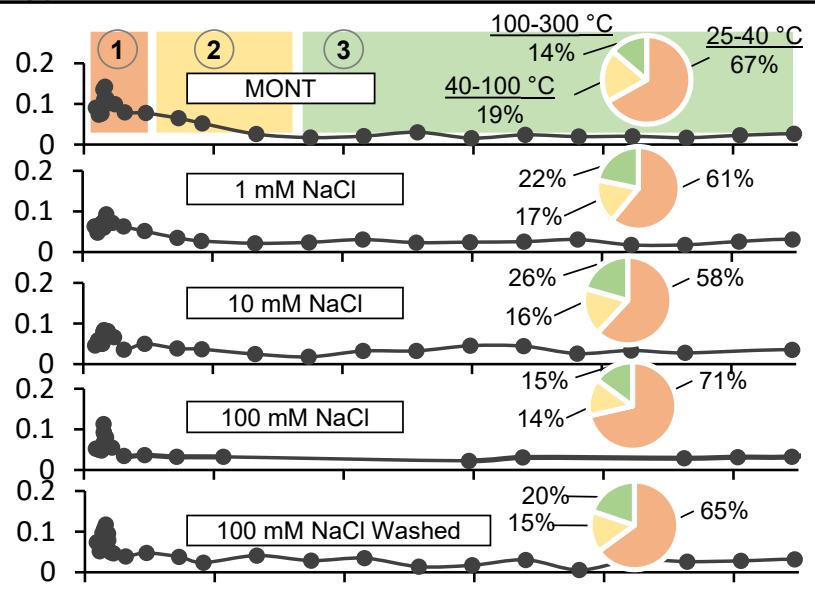

\section{5\% RH}

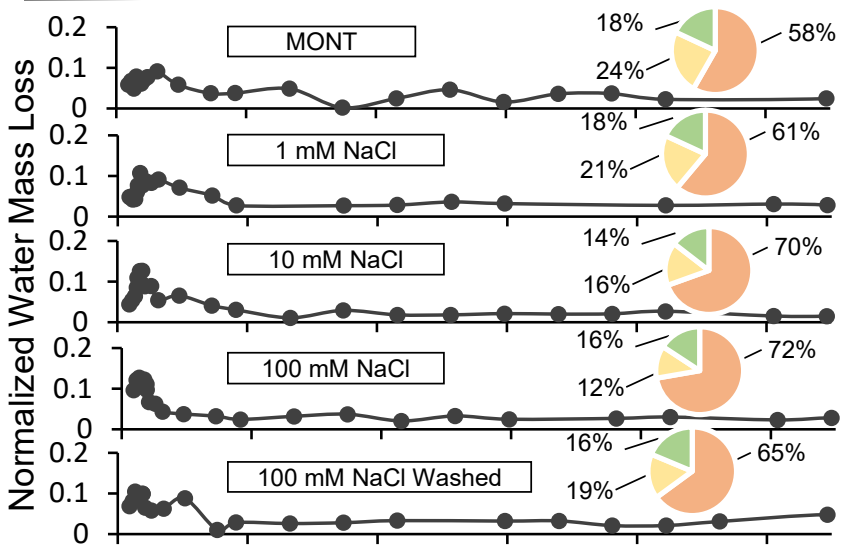

\section{$55 \%$ RH}

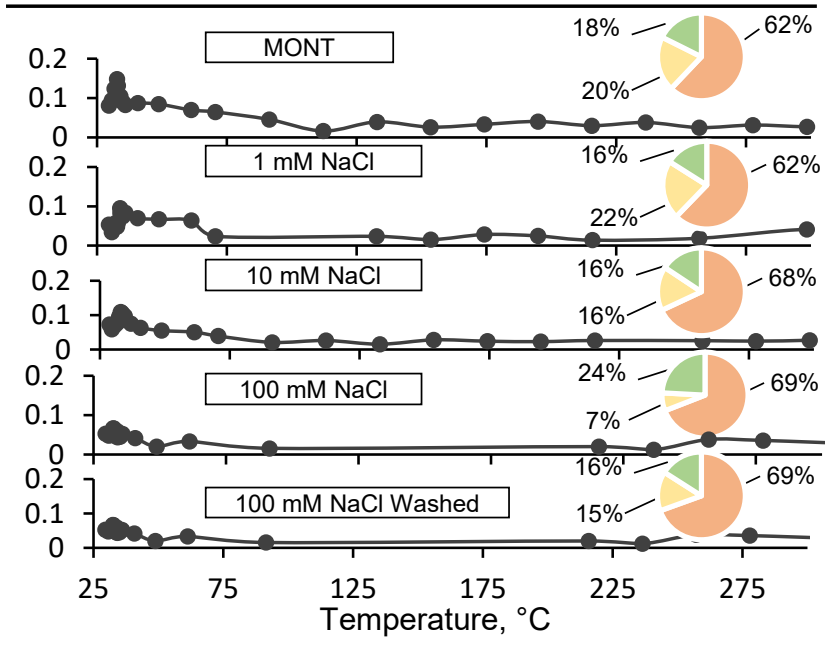

$33 \%$ RH

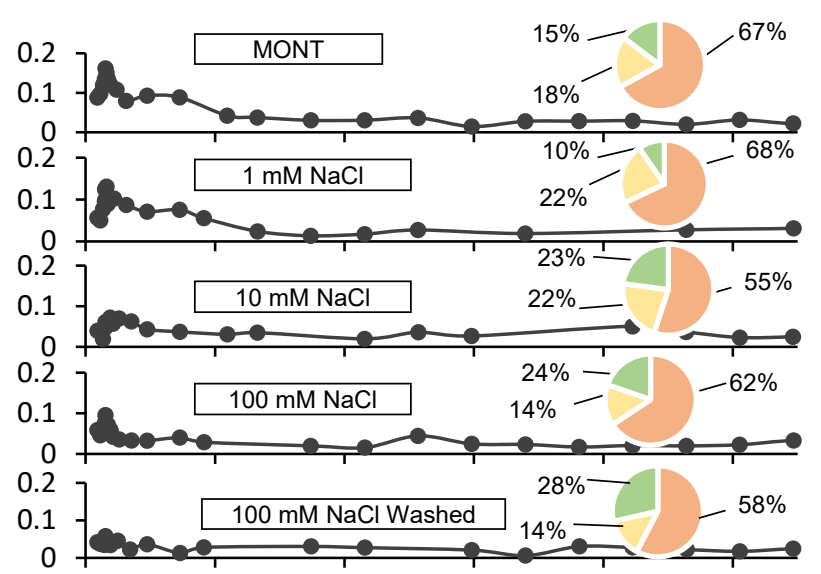

$11 \% \mathrm{RH}$

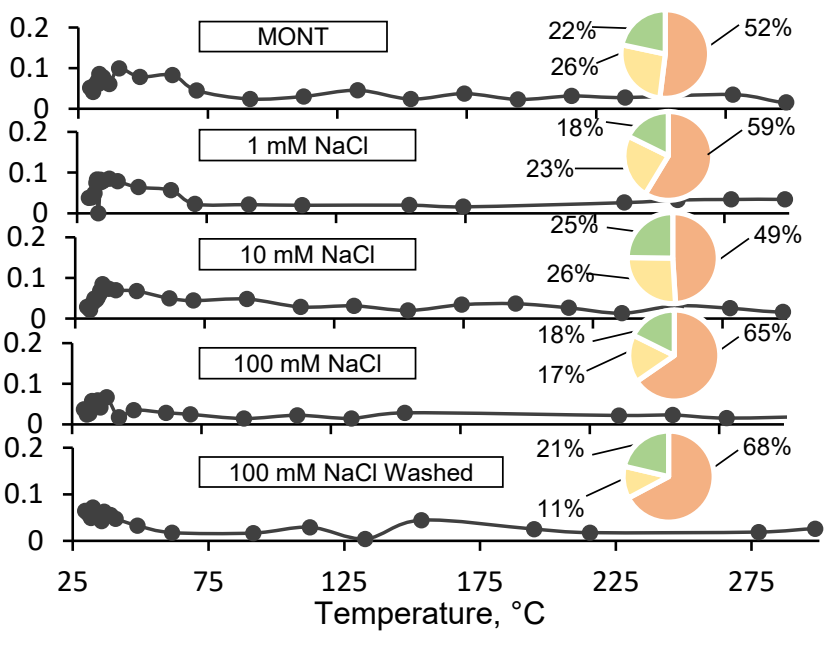

SI Figure E. Monitoring ion abundance $(\mathrm{m} / \mathrm{z}$ $18-\mathrm{H}_{2} \mathrm{O}$ ) for MONT control and MONT loaded with 1,10 , or $100 \mathrm{M} \mathrm{NaCl}$ as well as MONT loaded with $100 \mathrm{mM} \mathrm{NaCl}$ with an additional washing step. Spectra sectioned into freely-exchangeable water $\mathrm{T}=25$ to 40 ${ }^{\circ} \mathrm{C}$, loosely-bound water $\mathrm{T}=40$ to $100^{\circ} \mathrm{C}$, and tightly bound water $\mathrm{T}=100$ to $300^{\circ} \mathrm{C}$. Graphs are normalized by the structural $\mathrm{OH}$ mass loss $300-800{ }^{\circ} \mathrm{C}$. Pie charts show the percent of the total $25-300{ }^{\circ} \mathrm{C}$ normalized mass loss for each section. $\mathrm{Y}$-axis reflects normalized mass loss in $\mathrm{mg}$. 
SI Table D. Results from Thermogravimetric Analysis-Mass Spectrometry Monitoring of Water Loss (ion $\mathrm{m} / \mathrm{z} 18-\mathrm{H}_{2} \mathrm{O}$ ) from MONT loaded with $\mathrm{NaCl}$.

\begin{tabular}{|c|c|c|c|c|}
\hline Sample & Total Mass Loss $\mathrm{H}_{2} \mathrm{O}(\mathrm{mg})$ & Mass Loss $25-40^{\circ} \mathrm{C}$ & Mass Loss $40-100^{\circ} \mathrm{C}$ & Mass Loss $100-300^{\circ} \mathrm{C}$ \\
\hline MONT Control $11 \% \mathrm{RH}$ & 0.452 & 0.131 & 0.066 & 0.055 \\
\hline $1 \mathrm{mM} \mathrm{NaCl} 11 \% \mathrm{RH}$ & 0.169 & 0.0510 & 0.020 & 0.015 \\
\hline $10 \mathrm{mM} \mathrm{NaCl} 11 \% \mathrm{RH}$ & 0.320 & 0.0810 & 0.043 & 0.041 \\
\hline $100 \mathrm{mM} \mathrm{NaCl} 11 \% \mathrm{RH}$ & 0.122 & 0.0330 & 0.009 & 0.0090 \\
\hline $100 \mathrm{mM} \mathrm{NaCl}$ Washed $11 \% \mathrm{RH}$ & 0.0350 & 0.0110 & 0.0020 & 0.0030 \\
\hline MONT Control $33 \% \mathrm{RH}$ & 0.896 & 0.391 & 0.11 & 0.086 \\
\hline $1 \mathrm{mM} \mathrm{NaCl} 33 \% \mathrm{RH}$ & 0.283 & 0.112 & 0.037 & 0.016 \\
\hline $10 \mathrm{mM} \mathrm{NaCl} 33 \% \mathrm{RH}$ & 0.0850 & 0.0230 & 0.0090 & 0.0090 \\
\hline $100 \mathrm{mM} \mathrm{NaCl} 33 \% \mathrm{RH}$ & 0.257 & 0.0780 & 0.017 & 0.031 \\
\hline $100 \mathrm{mM} \mathrm{NaCl}$ Washed 33\% RH & 0.0830 & 0.0200 & 0.0050 & 0.010 \\
\hline MONT Control $55 \%$ RH & 0.842 & 0.332 & 0.11 & 0.094 \\
\hline $1 \mathrm{mM} \mathrm{NaCl} 55 \% \mathrm{RH}$ & 0.0880 & 0.0280 & 0.010 & 0.0070 \\
\hline $10 \mathrm{mM} \mathrm{NaCl} 55 \% \mathrm{RH}$ & 0.543 & 0.216 & 0.052 & 0.050 \\
\hline $100 \mathrm{mM} \mathrm{NaCl} 55 \% \mathrm{RH}$ & 0.0670 & 0.0220 & 0.0020 & 0.0080 \\
\hline $100 \mathrm{mM} \mathrm{NaCl}$ Washed 55\% RH & 0.0100 & 0.00300 & 0.0010 & 0.0010 \\
\hline MONT Control $75 \%$ RH & 0.220 & 0.0690 & 0.028 & 0.021 \\
\hline $1 \mathrm{mM} \mathrm{NaCl} 75 \% \mathrm{RH}$ & 0.192 & 0.0630 & 0.022 & 0.019 \\
\hline $10 \mathrm{mM} \mathrm{NaCl} 75 \% \mathrm{RH}$ & 0.207 & 0.0810 & 0.019 & 0.017 \\
\hline $100 \mathrm{mM} \mathrm{NaCl} 75 \% \mathrm{RH}$ & 0.441 & 0.187 & 0.031 & 0.041 \\
\hline $100 \mathrm{mM} \mathrm{NaCl}$ Washed $75 \% \mathrm{RH}$ & 0.150 & 0.0550 & 0.014 & 0.016 \\
\hline MONT Control $93 \%$ RH & 0.601 & 0.246 & 0.071 & 0.051 \\
\hline $1 \mathrm{mM} \mathrm{NaCl} 93 \% \mathrm{RH}$ & 0.507 & 0.165 & 0.047 & 0.059 \\
\hline $10 \mathrm{mM} \mathrm{NaCl} 93 \% \mathrm{RH}$ & 0.231 & 0.0710 & 0.020 & 0.032 \\
\hline $100 \mathrm{mM} \mathrm{NaCl} 93 \% \mathrm{RH}$ & 1.24 & 0.439 & 0.084 & 0.091 \\
\hline $100 \mathrm{mM} \mathrm{NaCl}$ Washed 93\% RH & 0.426 & 0.154 & 0.036 & 0.047 \\
\hline
\end{tabular}




\section{3\% RH}

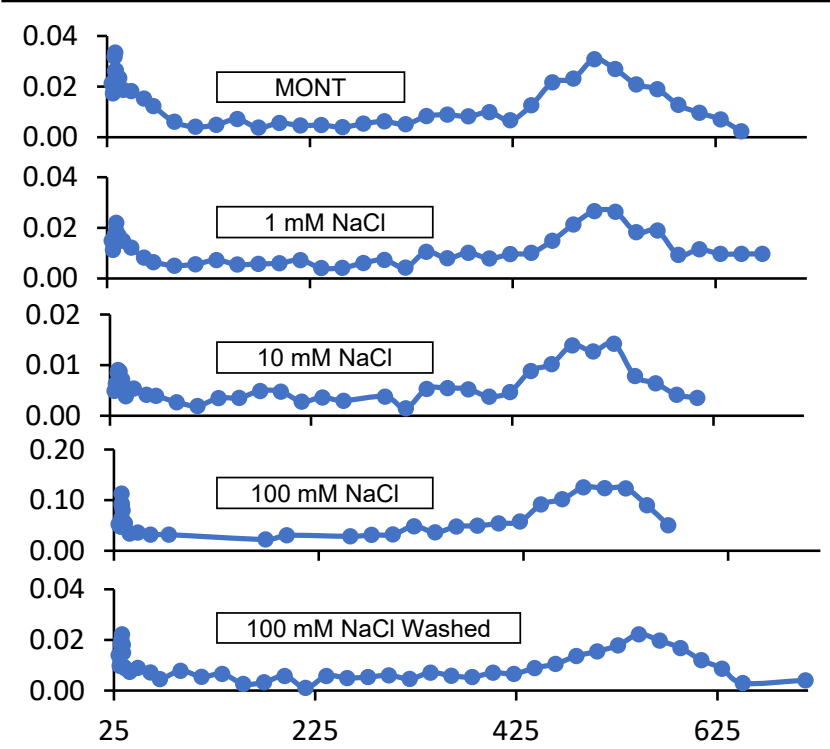

\section{5\% RH}

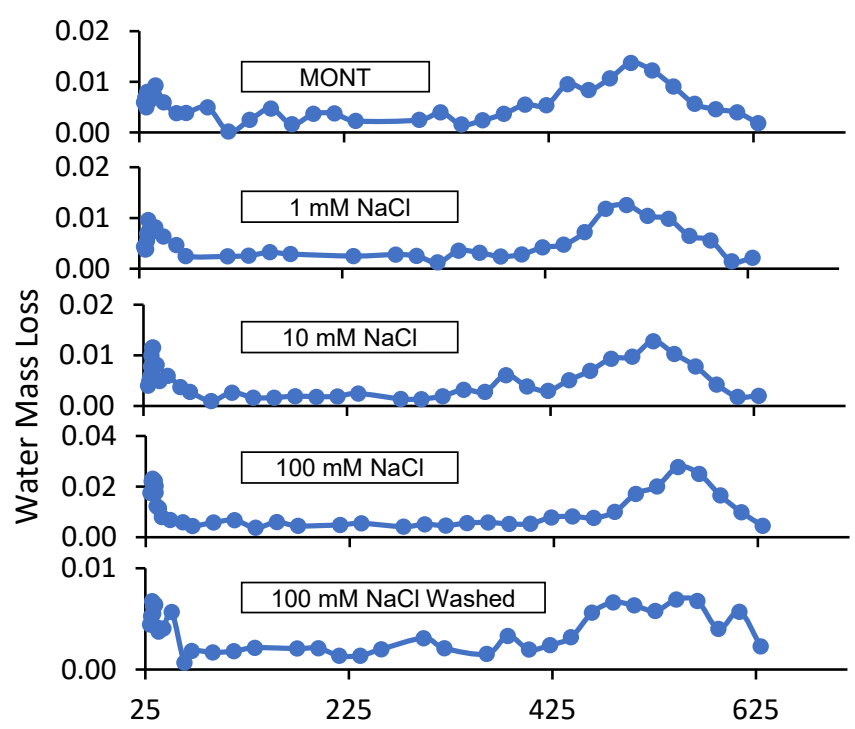

\section{$55 \%$ RH}

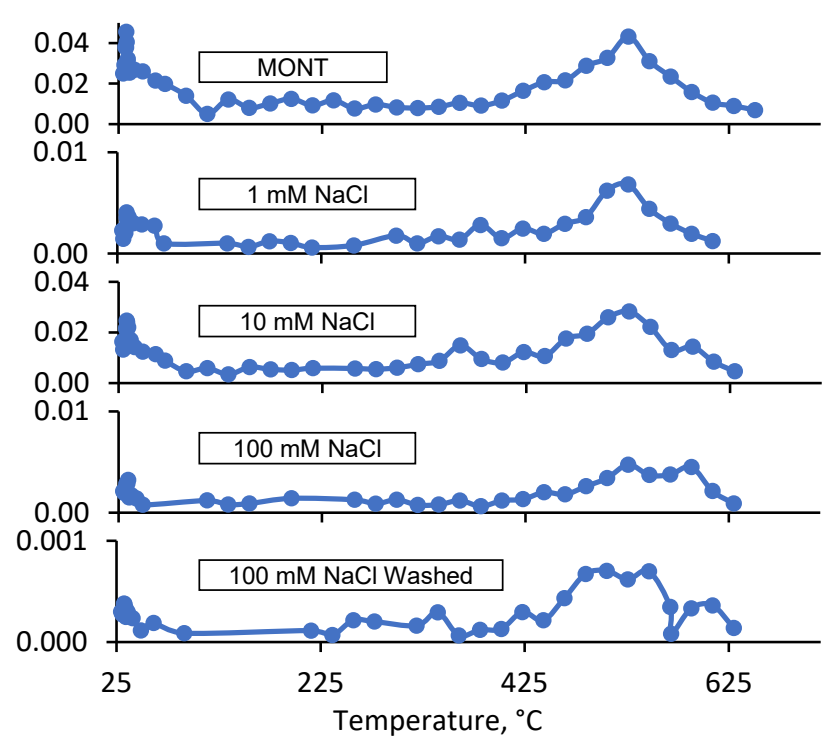

\section{$33 \%$ RH}
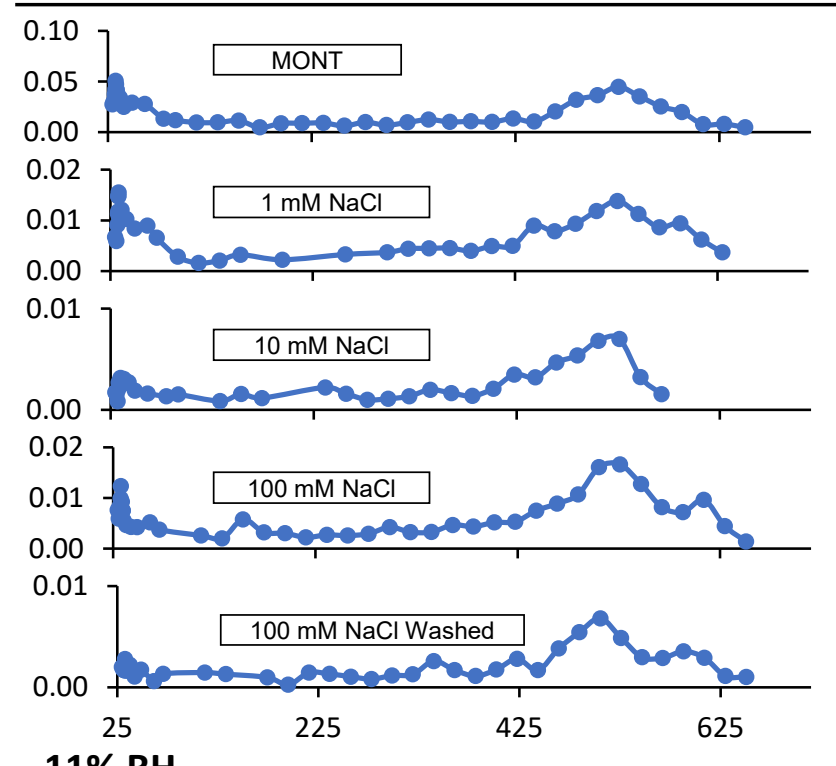

\section{$\underline{11 \% R H}$}

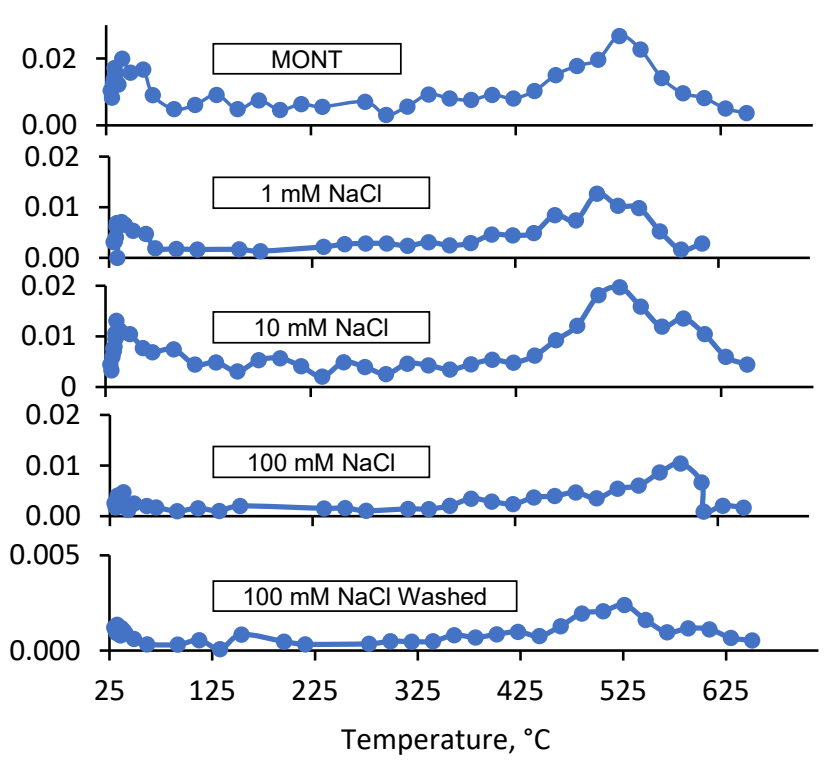

SI Figure F. Monitoring ion abundance $(\mathrm{m} / \mathrm{z} 18$ $\mathrm{H}_{2} \mathrm{O}$ ) for MONT control and MONT loaded with 1 , 10 , or $100 \mathrm{M} \mathrm{NaCl}$ as well as MONT loaded with $100 \mathrm{mM} \mathrm{NaCl}$ with an additional washing step. Yaxis reflects mass loss in $\mathrm{mg}$. 


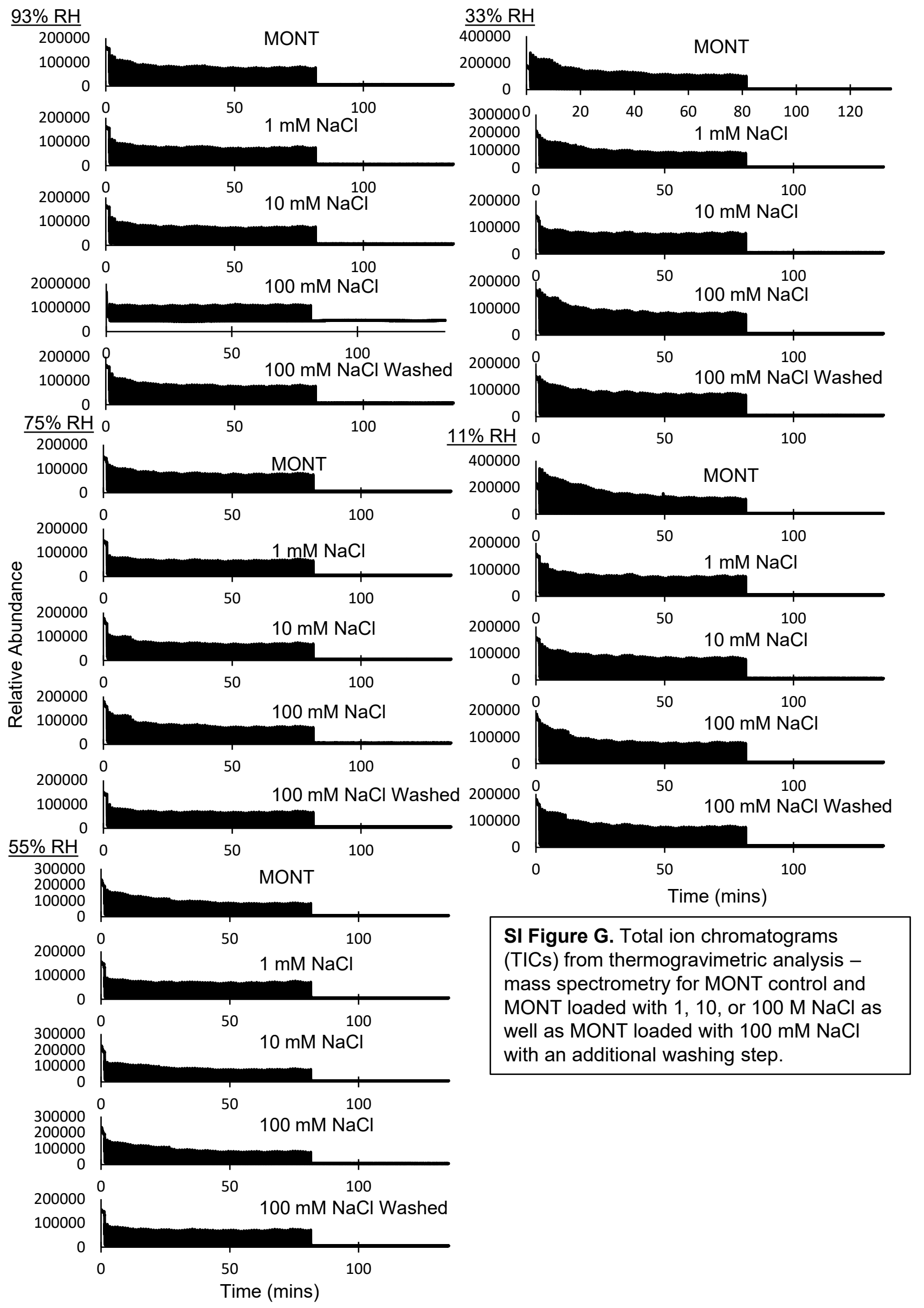




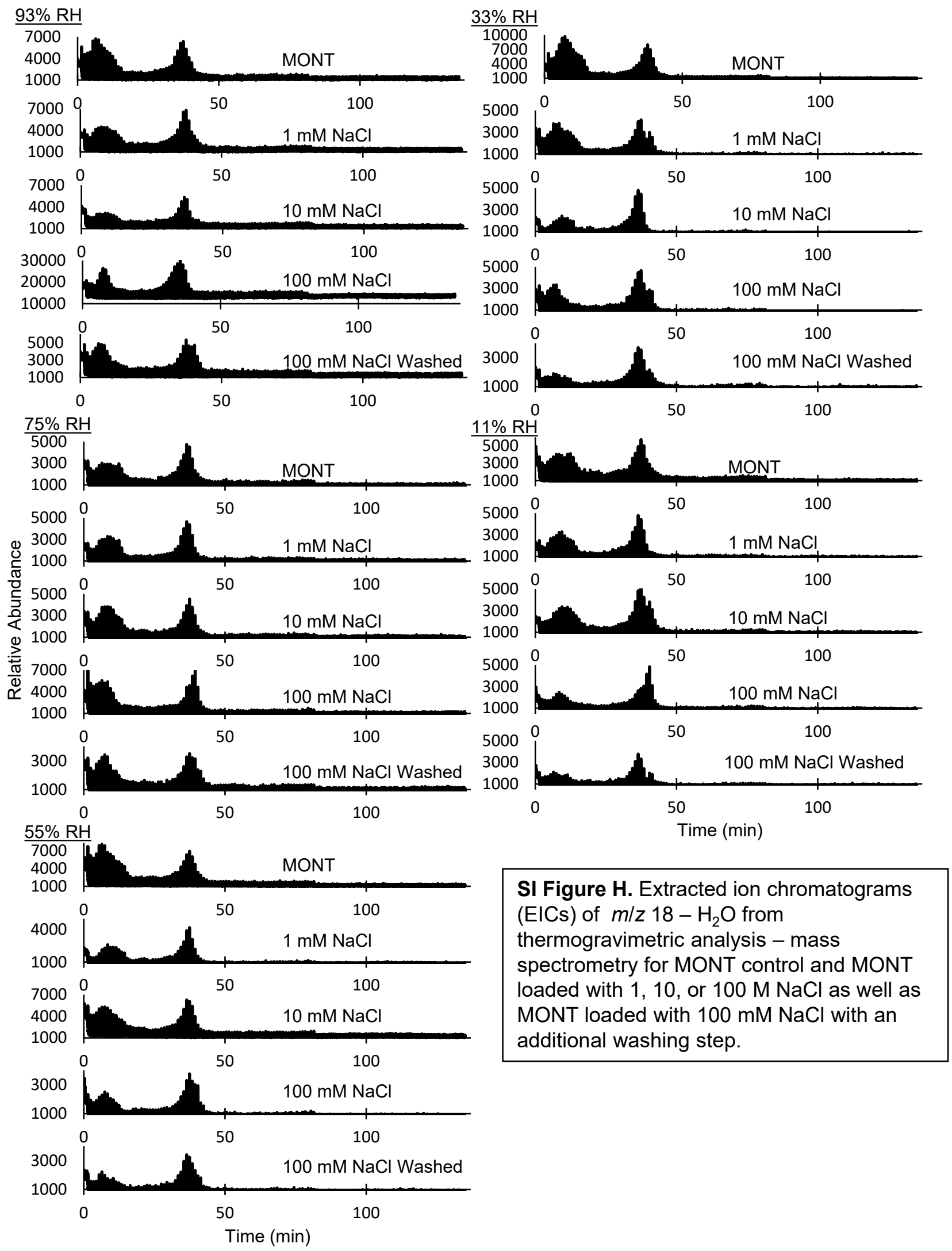




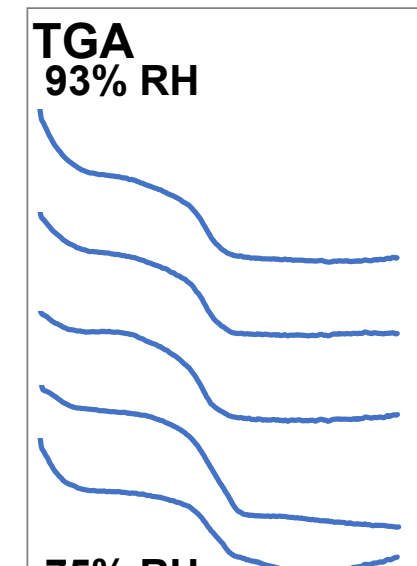

$75 \%$ RH

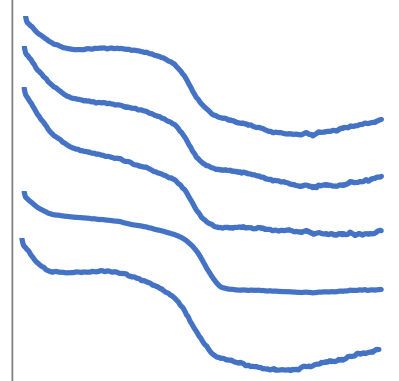

$55 \%$ RH

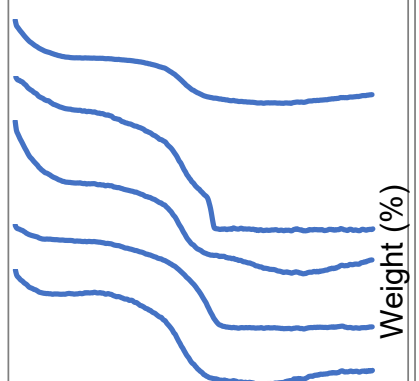

$33 \% \mathrm{RH}$
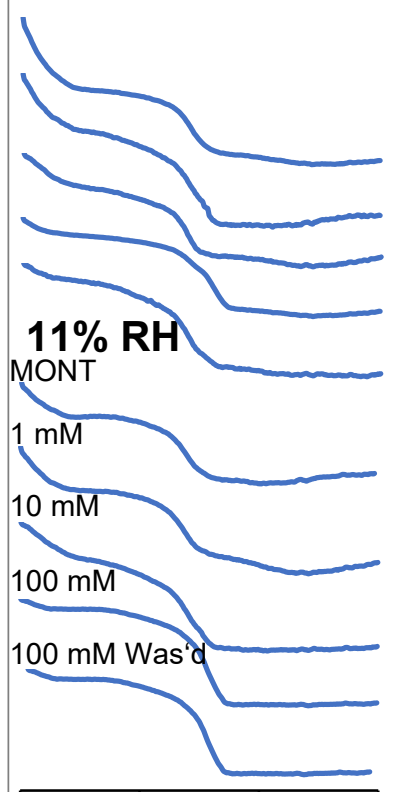

$0 \quad 500 \quad 1000 \quad 1500$ Temperature, ${ }^{\circ} \mathrm{C}$

\section{DTGA \\ $93 \%$ RH}

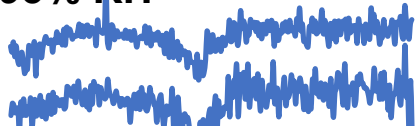

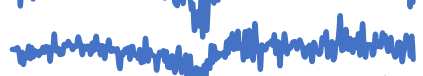

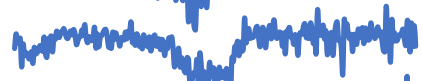

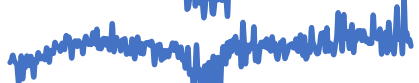

\section{$75 \%$ RH} warimenth (1) IN

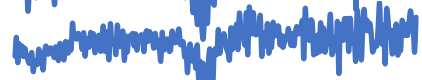
年

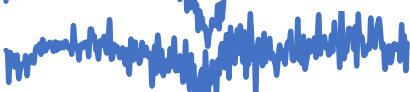

\section{$55 \%$ RH}

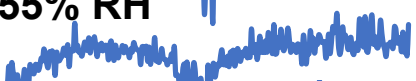

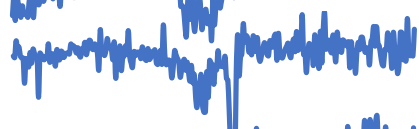

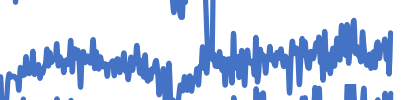

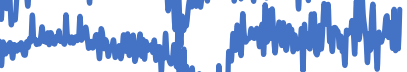

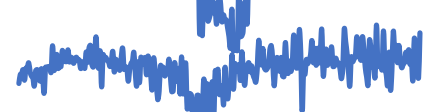
$33 \% \mathbf{R H}$

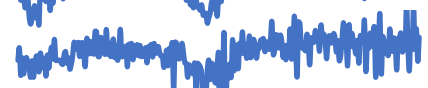

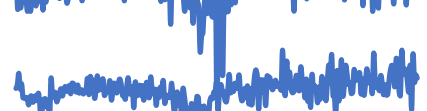

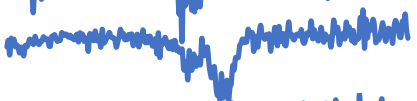

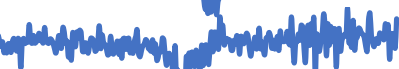
$11 \%$ RH

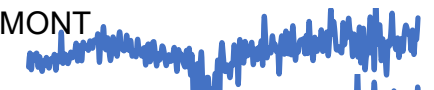
$1 \mathrm{mM}$ mannm

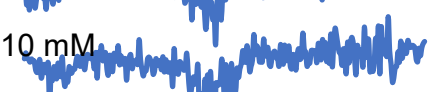

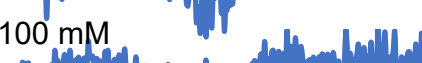

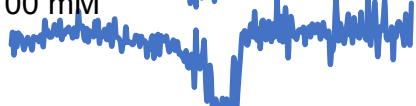
100 mM Was'd

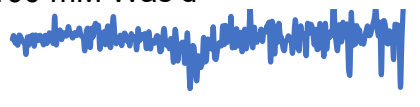
$500 \quad 1000$
Temperature, ${ }^{\circ} \mathrm{C}$

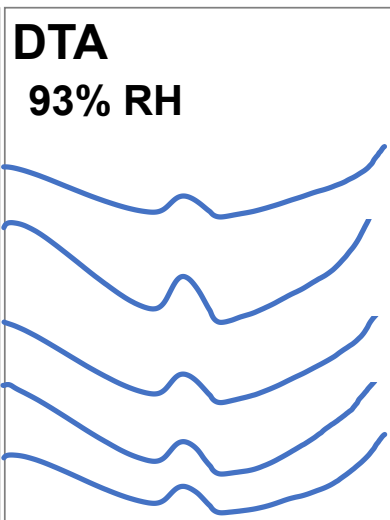

\section{5\% RH}
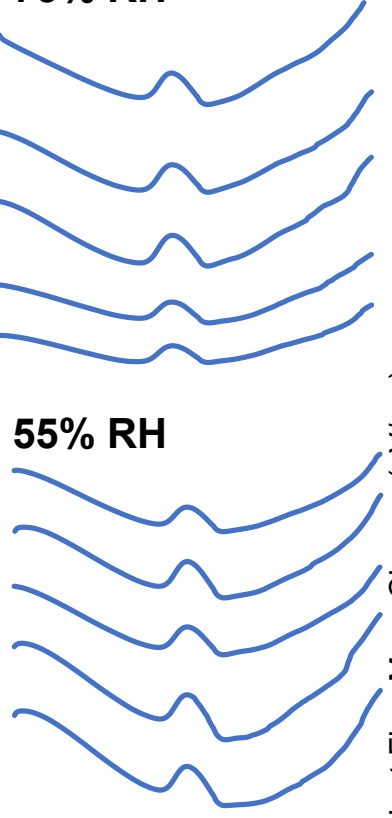

\section{$33 \% \mathrm{RH}$}

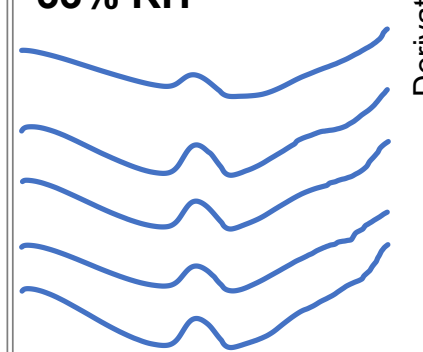

\section{$11 \% \mathrm{RH}$}

MONT

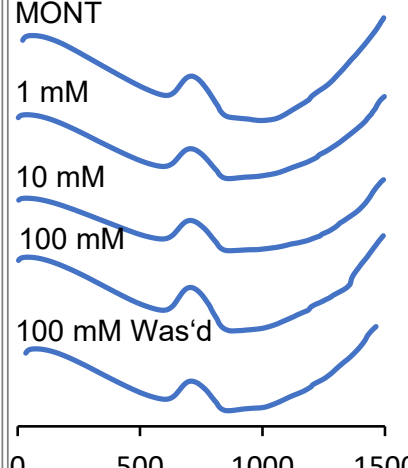

\section{DDTA}

93\% RH

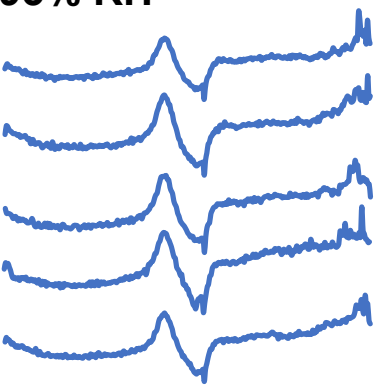

\section{$75 \% \mathrm{RH}$}

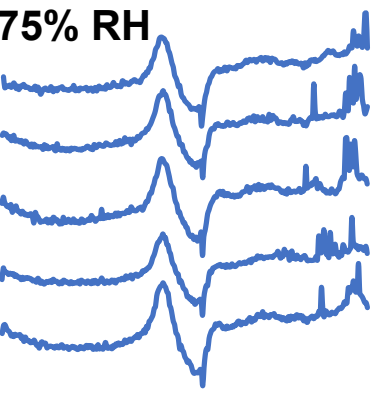

\section{$55 \%$ RH}
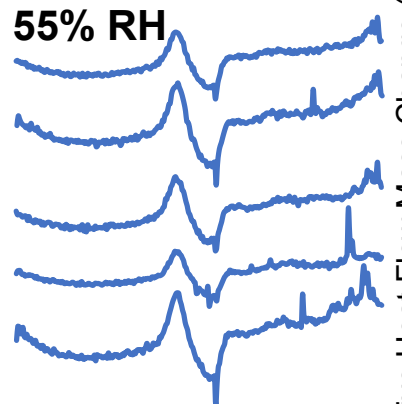

$33 \% \mathrm{RH}$

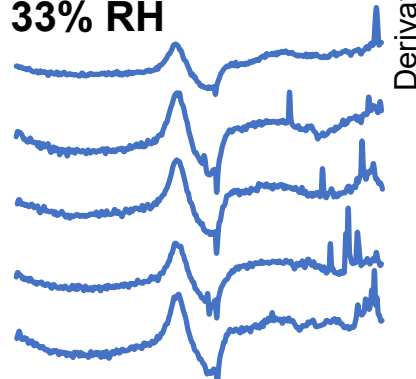

$11 \%$ RH

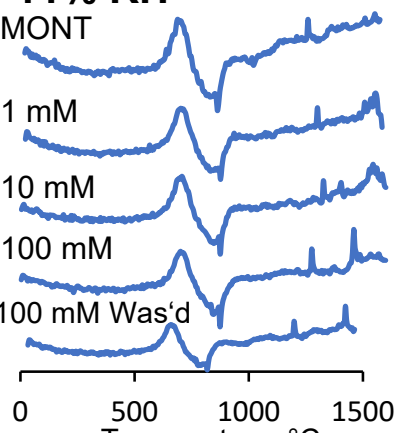

SI Figure I.

Thermogravimetric mass loss patterns (TGA) as well as their derivatives (DTGA) for MONT control and MONT loaded with 1,10 , or $100 \mathrm{M} \mathrm{NaCl}$ as well as MONT loaded with 100 $\mathrm{mM} \mathrm{NaCl}$ with an additional washing step. Differential thermal analysis (DTA) collected simultaneously during TGA experiments shown as well as the derivative graph (DDTA). 


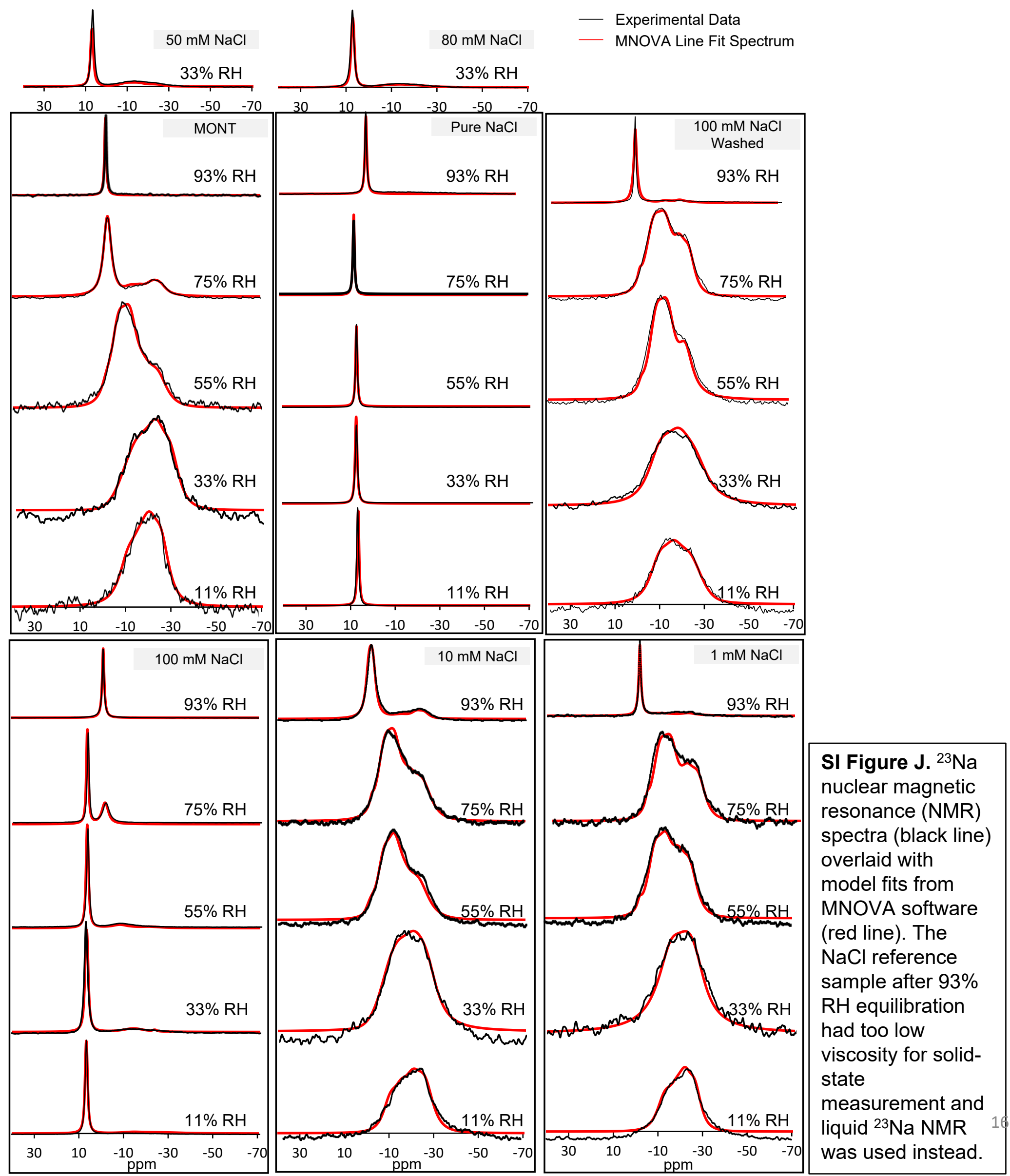




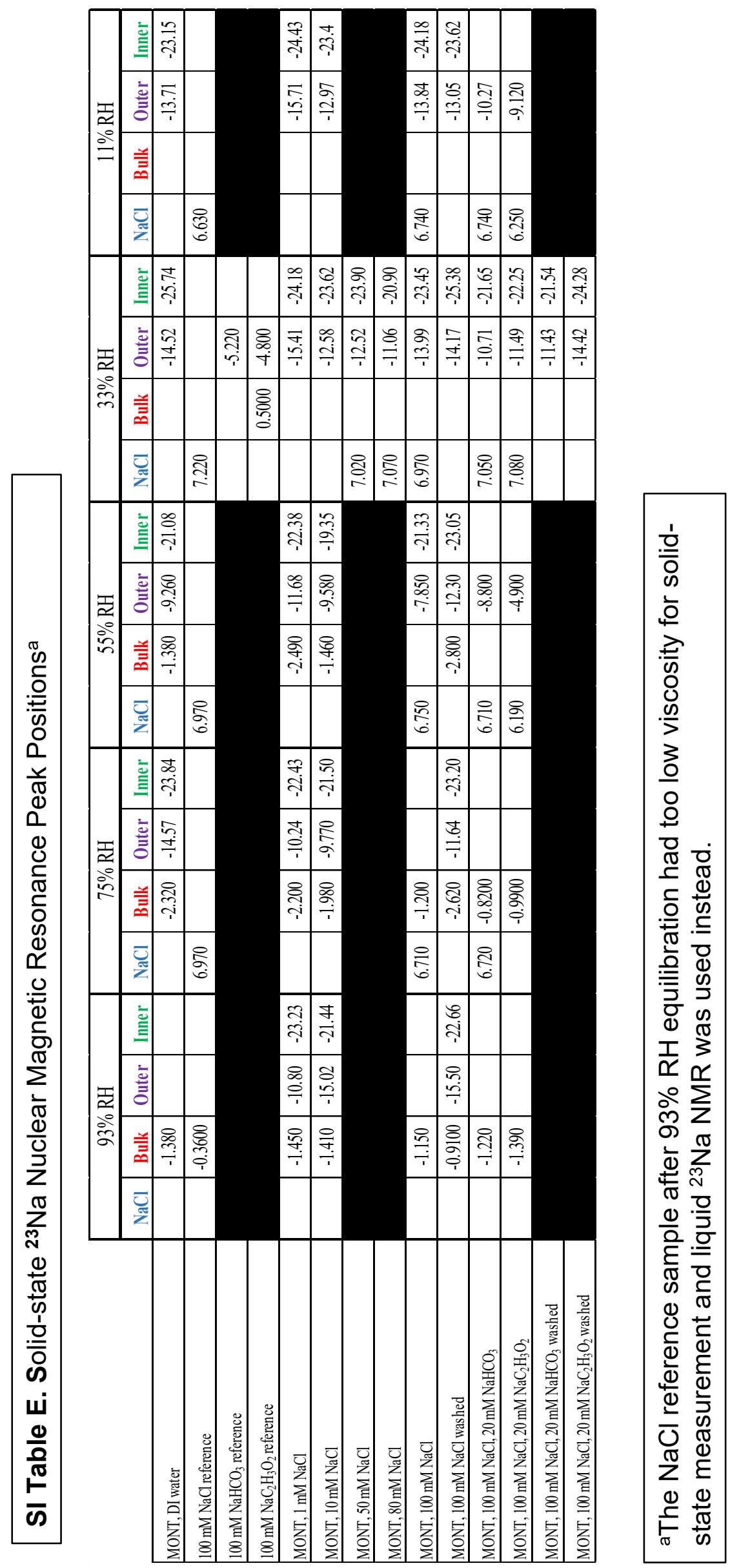


$93 \% \mathrm{RH}$

$75 \% \mathrm{RH}$

$55 \% \mathrm{RH}$

$33 \% \mathrm{RH}$

$11 \% \mathrm{RH}$

MONT loaded with $100 \mathrm{mM} \mathrm{NaCl}$ and $20 \mathrm{mM} \mathrm{NaHCO}_{3}$
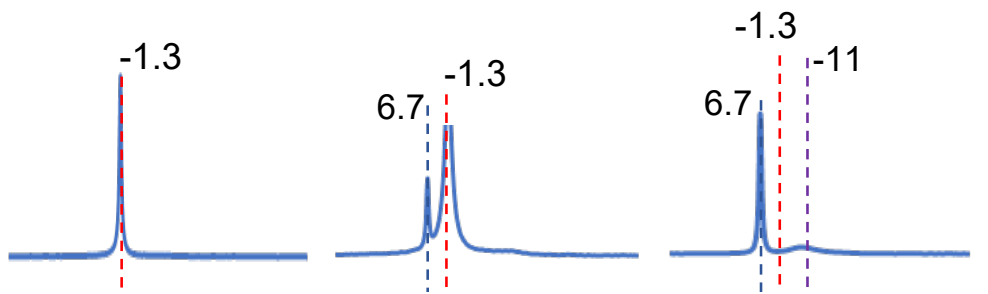

MONT loaded with $100 \mathrm{M} \mathrm{NaCl}$ and $20 \mathrm{mM} \mathrm{NaC}_{2} \mathrm{H}_{3} \mathrm{O}_{2}$
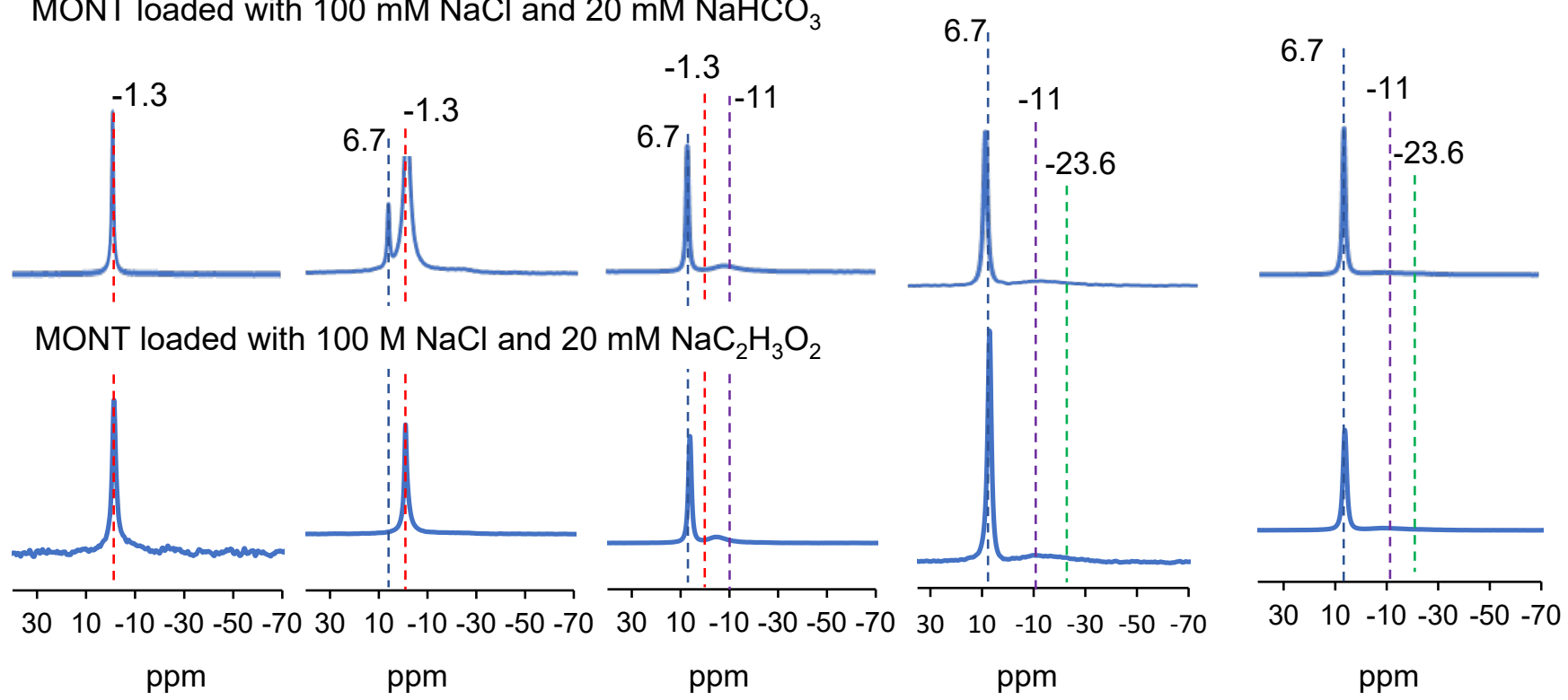

SI Figure K. Solid-state ${ }^{23} \mathrm{Na}$ nuclear magnetic resonance data of MONT loaded with $\mathrm{NaCl}$ and in buffer solution after $\mathrm{RH}$ equilibration 
MONT loaded with $100 \mathrm{mM} \mathrm{NaCl}$ and $20 \mathrm{mM} \mathrm{NaHCO}_{3}$

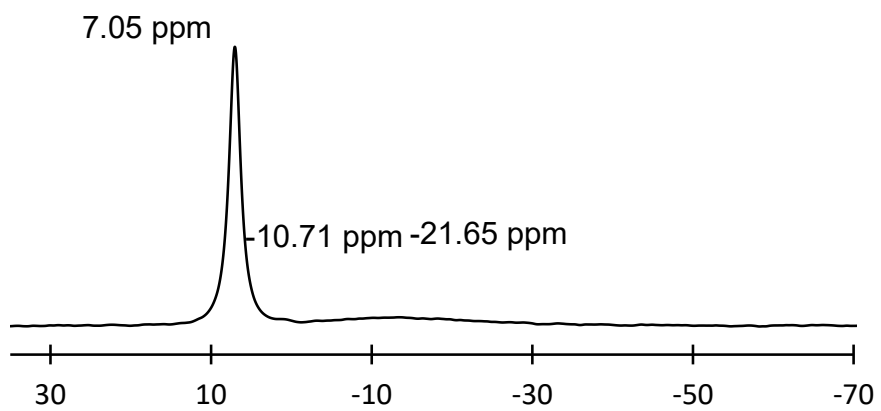

MONT loaded with $100 \mathrm{mM} \mathrm{NaCl}$ and $20 \mathrm{mM} \mathrm{NaHCO}_{3}$ washed

-11.43 ppm -21.54 ppm

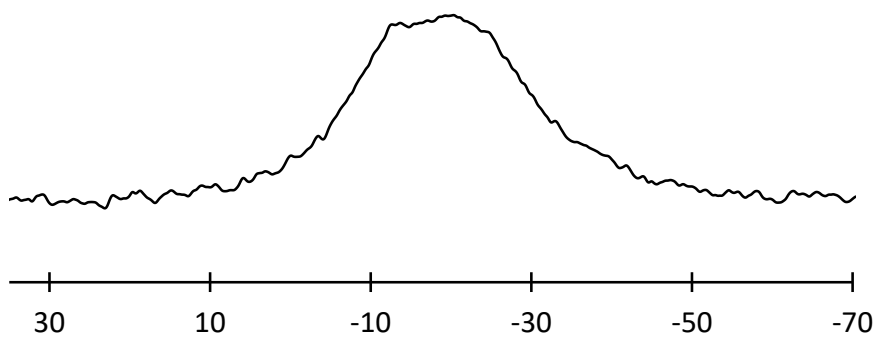

MONT loaded with $100 \mathrm{mM} \mathrm{NaCl}$ and $20 \mathrm{mM} \mathrm{NaC}_{2} \mathrm{H}_{3} \mathrm{O}_{2}$

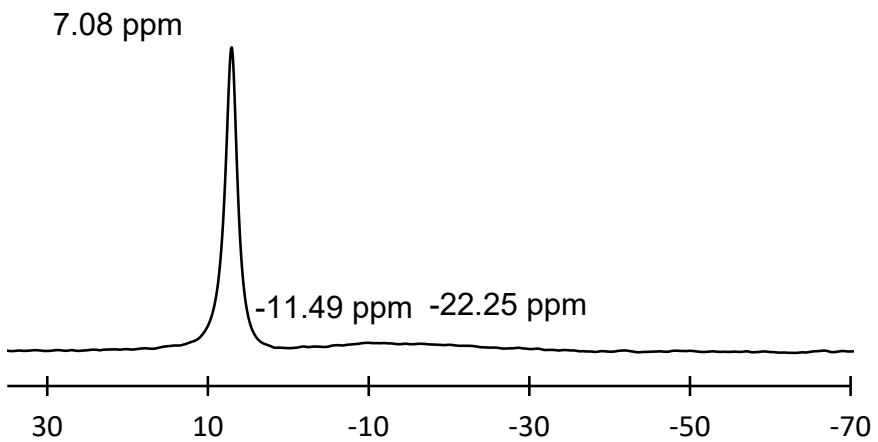

MONT loaded with $100 \mathrm{mM} \mathrm{NaCl}$ and $20 \mathrm{mM} \mathrm{NaC}{ }_{2} \mathrm{H}_{3} \mathrm{O}_{2}$ washed

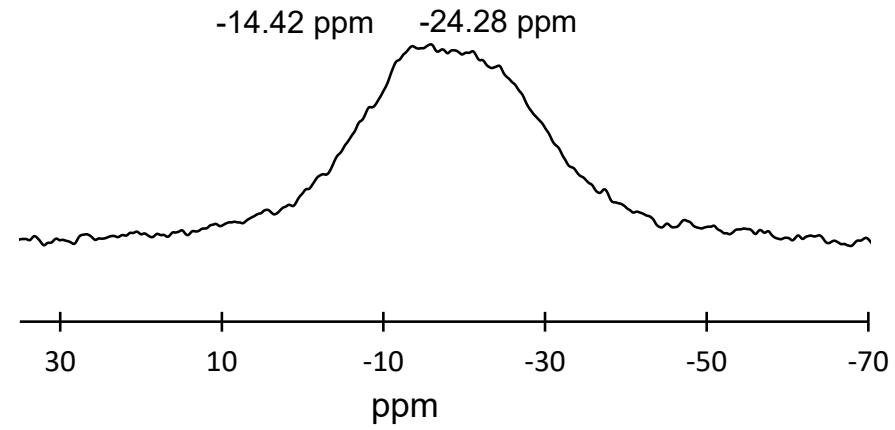

SI Figure L. Solid-state ${ }^{23} \mathrm{Na}$ nuclear magnetic resonance data of MONT loaded with $\mathrm{NaCl}$ and in buffer solution after $33 \% \mathrm{RH}$ equilibration with and without a washing procedure 

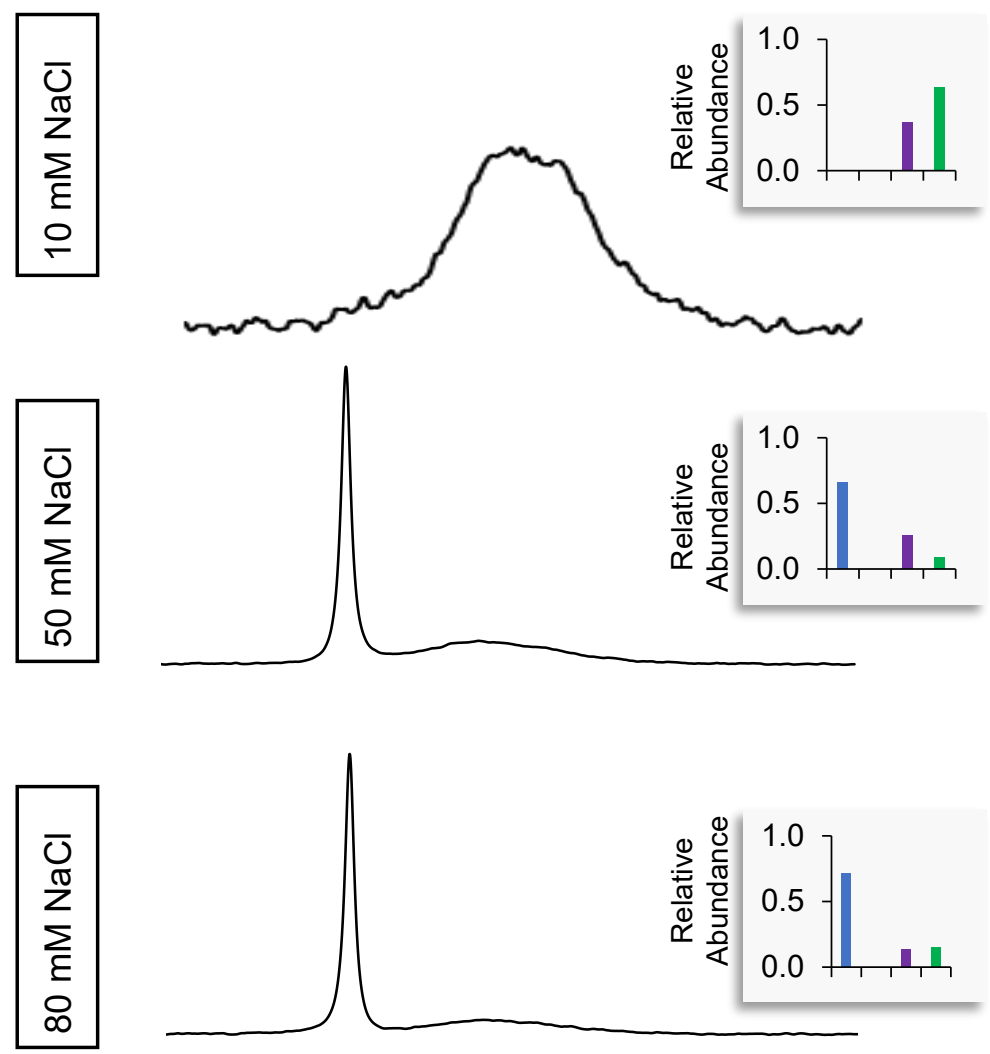

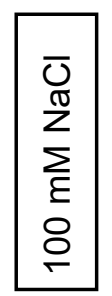

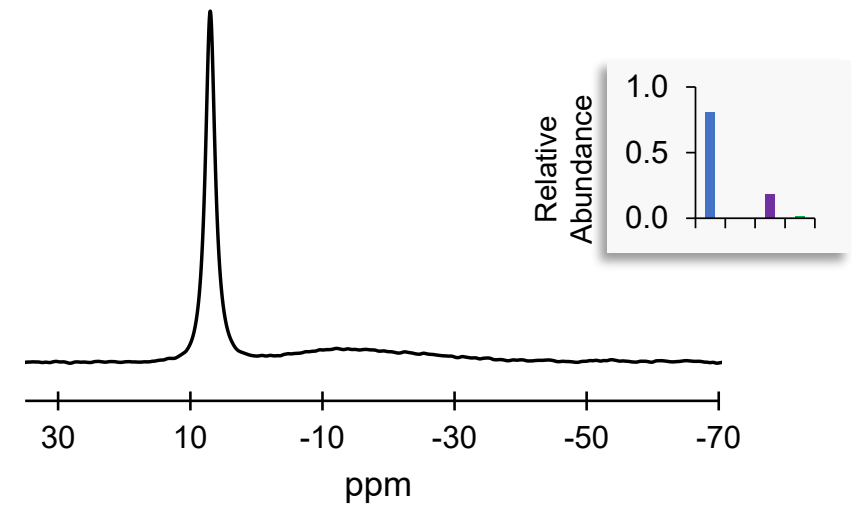

SI Figure M. Solid-state ${ }^{23} \mathrm{Na}$ nuclear magnetic resonance data of MONT loaded with $100,80,50$, or $10 \mathrm{mM} \mathrm{NaCl}$ at $33 \% \mathrm{RH}$. Peak distribution abundances from MNOVA line fitting included. 
Liquid-state ${ }^{23} \mathrm{Na} \mathrm{NMR}$ measurement pure $\mathrm{NaCl}$ at $93 \% \mathrm{RH}$

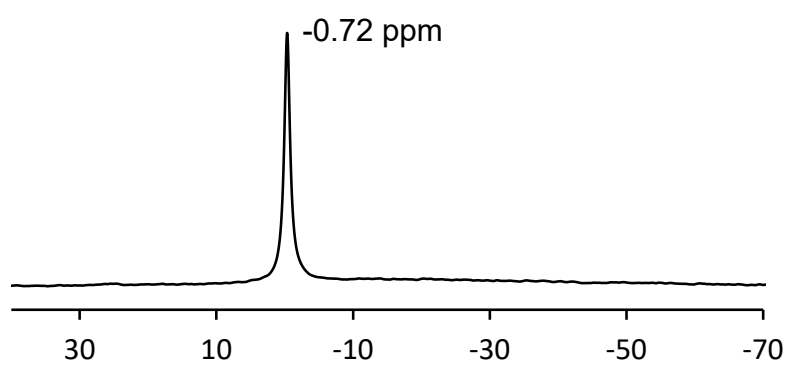

Solid-state ${ }^{23} \mathrm{Na}$ NMR measurement of MONT loaded with 100 $\mathrm{mM} \mathrm{NaCl}$ and $20 \mathrm{mM} \mathrm{NaHCO}_{3}$ at $33 \% \mathrm{RH}$

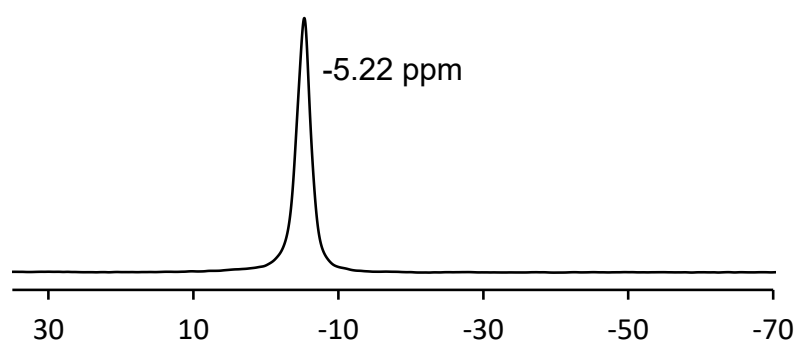

Solid-state ${ }^{23} \mathrm{Na}$ NMR measurement of MONT loaded with 100 $\mathrm{mM} \mathrm{NaCl}$ and $20 \mathrm{mM} \mathrm{NaC}_{2} \mathrm{H}_{3} \mathrm{O}_{2}$ at $33 \% \mathrm{RH}$

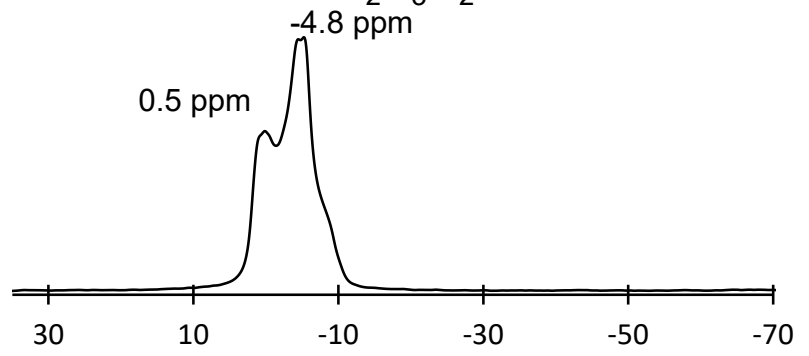

Solid-state ${ }^{23} \mathrm{Na} \mathrm{NMR}$ measurement of pure reference $\mathrm{NaCl}$ at $33 \%$

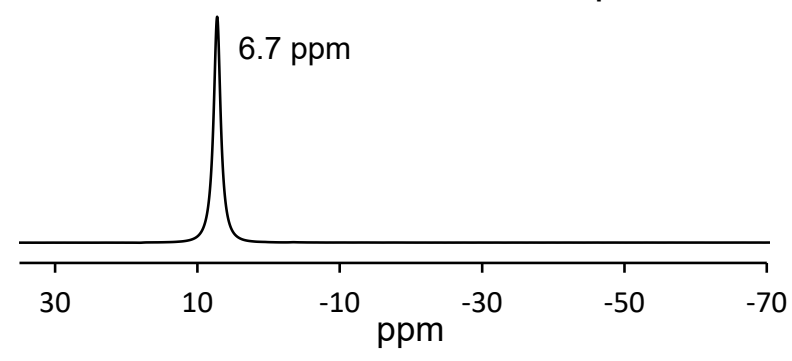

SI Figure N. ${ }^{23} \mathrm{Na}$ nuclear magnetic resonance data of MONT loaded with $\mathrm{NaCl}$ and in buffer solution compared to pure $\mathrm{NaCl}$ reference spectra. The $\mathrm{NaCl}$ reference sample after $93 \% \mathrm{RH}$ equilibration had too low viscosity for solid-state measurement and liquid ${ }^{23} \mathrm{Na}$ NMR was used instead. 

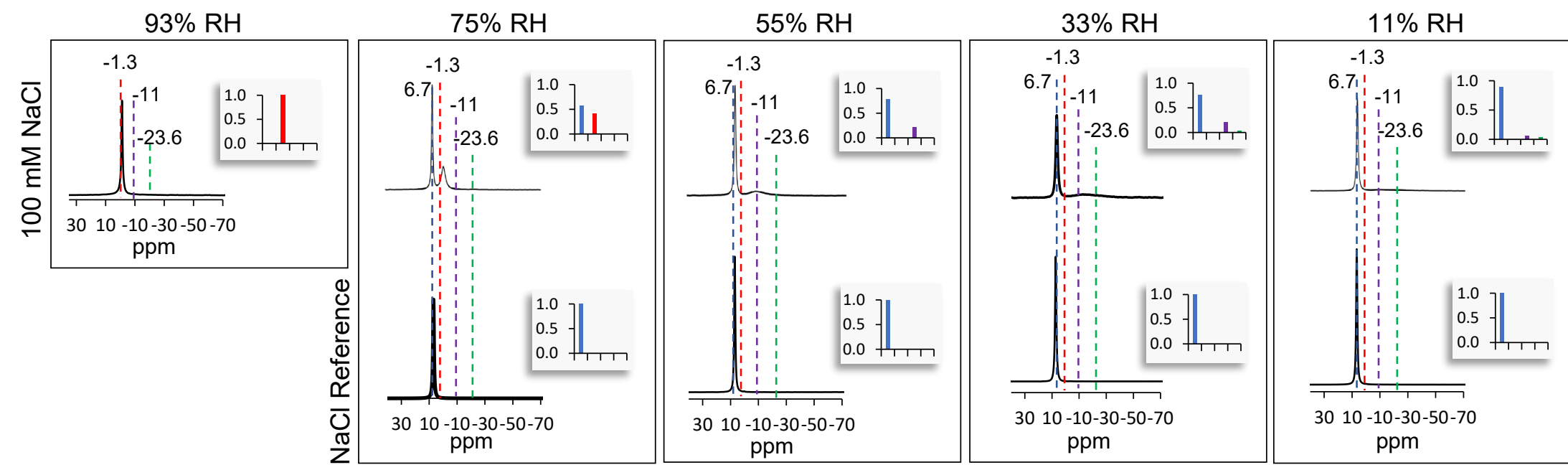

SI Figure $\mathbf{O}$. RH-dependent solid-state ${ }^{23} \mathrm{Na}$ NMR data of pure $\mathrm{NaCl}$ and MONT loaded with $100 \mathrm{mM} \mathrm{NaCl}$. Peak distribution abundances from MNOVA line fitting included. The $\mathrm{NaCl}$ reference sample after $93 \% \mathrm{RH}$ equilibration had too low viscosity for solid-state measurement. 